\title{
Neuroscience and Criminal Justice: Not Responsibility but Treatment
}

\author{
Henry T. Greely*
}

Frontal leucotomy, despite certain limitations of the operative method, must be considered one of the most important discoveries ever made in psychiatric therapy, because through its use a great number of suffering people and total invalids have recovered and have been socially rehabilitated.

The Nobel Prize in Physiology or Medicine 1949 Presentation Speech ${ }^{1}$

\section{INTRODUCTION}

In 1949 Egas Moniz won the Nobel Prize for inventing the procedure commonly known as the prefrontal lobotomy. Within twenty-five years, the procedure was both generally abandoned and widely reviled.

Today we are regularly making new discoveries about the functioning of the human brain, discoveries that have led many lawyers, philosophers, and neuroscientists to speculate about the consequences of our new understanding for the criminal justice system. ${ }^{2}$ Their attention has focused almost exclusively on questions of responsibility and their conclusions have ranged from apocalyptic ${ }^{3}$ to "business as usual." $\mathrm{I}$, too, believe that advances in neuroscience will change, dramatically, the criminal justice system, but I expect issues of responsibility to play a

\footnotetext{
* Deane F. and Kate Edelman Johnson Professor of Law, Professor (by courtesy) of Genetics, Stanford University. The author would like to thank two research assistants for their able help with this paper: Sean Johnson and Kelly Lowenberg.

1. H. Olivecrona, Presentation Speech, Nobel Prize in Physiology or Medicine 1949, available at http://nobelprize.org/nobel_prizes/medicine/laureates/1949/press.html.

2. E.g., Joshua Greene \& Jonathan Cohan, For the Law, Neuroscience Changes Nothing and Everything, 359 PhIL. TRANSACT. ROYAL SOC'Y LONDON B 1775 (2004); Dean Mobbs et al., Law, Responsibility, and the Brain, 5 PLoS BIOL 693-99 (2007); Stephen J. Morse, Brain Overclaim Syndrome and Criminal Responsibility: A Diagnostic Note, 3 OHIO ST. J. CRIM. L. 397 (2006); Robert M. Sapolsky, The Frontal Cortex and the Criminal Justice System, 359 PhIL. TRANSACT. Royal SOC'Y LONDON B 1787 (2004).

3. Sapolsky, supra note 2.

4. Morse, supra note 2.
} 
small role in those changes - and an overly strong focus on responsibility to draw attention away from more important and troubling areas.

Neuroscientific evidence about the links between brain dysfunction and criminal behavior seems, to me, unlikely to change our lay views of the demands of justice or to touch the non-retributive justifications for invoking a criminal justice system: deterrence, incapacitation, and rehabilitation. Instead, we may see major changes in how crimes are investigated, in how trials are conducted, in how sentencing decisions are reached, and in what kinds of sentences are imposed. Lie detection and other forms of "mind-reading" may be used to investigate crimes. ${ }^{5}$ Trials may be affected both by the introduction of such mind-reading evidence and by neuroscientific evidence of bias, on the part of parties, witnesses, jurors, and even judges. ${ }^{6}$ Issues of psychopathy, frontal lobe damage, and other asserted "causes" of criminal behavior may be used, not to reduce responsibility, but as predictive factors to increase sentences. ${ }^{7}$ And neuroscience, defined broadly, may provide us with new options in sentencing that hold out the promise of effective rehabilitation through treatment. ${ }^{8}$

This essay examines only the last of those issues-the possible consequences of neuroscience for the kinds of sentences that may be imposed on convicted criminals. I argue that neuroscience is likely to produce a number of different types of interventions-surgical, pharmacological, and other - that will be said to prevent, or to lessen the risk of, continuing criminal conduct. These interventions will be tempting for both their promise of rehabilitation-making the criminal a good and useful member of society-and their promise of

5. See, e.g., Henry T. Greely, Prediction, Litigation, Privacy, and Property: Some Possible Legal and Social Implications of Advances in Neuroscience, in NEUROSCIENCE AND THE LAW 114, 128-32 (Brent Garland, ed., 2004) [hereinafter Greely, Litigation]; Henry T. Greely, Neuroethics and ELSI: Similarites and Differences, 7 MinN. J.L. SCI. \& TECH. 599, 614, 632 (2006); Henry T. Greely \& Judy Illes, NEUROSCIENCE-BASED LIE DETECTION: THE URGENT NEED FOR REGULATION, 33 AM. J.L. \& MED., 377 (2007); Paul Root Wolpe, et al., Emerging Nerotechnologies for LieDetection: Promises and Perils, AM. J. BioETHICs, Mar.-Apr. 2005, at 39.

6. Greely, Litigation, supra note 5, at 128-37 (discussing mind-reading evidence); id. at 13738 (discussing evidence of bias).

7. I recently organized a seminar for federal judges on legal issues in genetics and neuroscience. It was striking how uninterested judges were in violence-inducing brain conditions for issues of responsibility, sanity, and so on, and how very interested they were in those same questions in terms of sentencing decisions. Ironically, what might be set out as a mitigating factor for a defendant in terms of responsibility is likely to increase the sentence for a convicted criminal.

8. The connection between neuroscientific treatments and rehabilitation is not essential. One could imagine that someone who viewed retribution as the (or at least $a$ ) main purpose of criminal sentencing being interested in using neuroscience to make a sentence more painful and punitive. This essay will not walk those dark paths - but they probably exist. 
incapacitation-preventing him, in a way more powerful than any prison walls, from committing more crimes. ${ }^{9}$

I am not a scholar of the criminal justice system and I will not delve into the long and deep discussions of the different justifications for that system. Instead, I will use what I know about neuroscience to lay out the plausible kinds of brain-based interventions that may be suggested (or are already being used) to prevent criminal behavior. ${ }^{10}$ I will then lay out the problems involved in trying to determine whether such interventions are safe and effective. These problems will be enormous and probably under-appreciated. My main argument is that we need to be vigilant to avoid the over-enthusiastic adoption of unproven new "treatments"practiced in the brains of, at best, unsympathetic and, at worst, despised people.- I will end with a brief discussion of some of the normative issues that would have to be addressed if we found safe and effective interventions. But those issues lie, largely though not entirely, beyond the horizon. For now, we need to worry about safety and effectiveness and to learn from past failures, like the prefrontal lobotomy, if we are to have any chance to avoid misuse of new techniques.

\section{NEUROSCIENCE AND THE “TREATMENT” OF CRIMINALS}

Our increasing understanding of the brain is producing new ways to intervene in human behavior - to change minds by directly changing

9. John Stinneford, in a recent article on chemical castration, quoted a lovely way of expressing the comparative strength of prisons versus brains:

In 1642, during his imprisonment for presenting a royalist petition to the rebellious House

of Commons, the cavalier poet Richard Lovelace wrote the following, now-famous lines:

Stone walls do not a prison make,

Nor iron bars a cage;

Minds innocent and quiet take

That for an hermitage;

If I have freedom in my love

And in my soul am free,

Angels alone, that soar above,

Enjoy such liberty.

John F. Stinneford, Incapacitation Through Maiming: Chemical Castration, the Eighth Amendment, and the Denial of Human Dignity, 3 U. ST. ThOMAS L.J. 559, 560 (2006) (quoting Richard Lovelace, To Althea: From Prison, in The Oxford Book of English Verse 1250-1900 374 (Arthur QuillerCouch, ed., Oxford U. Press 1919)).

10. There is a long history of discussion of, and concern about, various methods of "mind control" being used in the criminal justice system, including such psychological methods as aversive therapy. (Aversive therapy was the method used in the famous novel (and movie), A Clockwork Orange. ANTHONY BURGESS, A ClOCKWORK ORANGe (1962).) I will not discuss that history in this essay. 
brains. We can directly change brains in at least four different ways: neurosurgery, deep brain stimulation, drugs, and vaccines. At least some uses of those methods may be able to reduce some kinds of criminal behavior. The following discussion is necessarily quite speculative. The best-understood examples are pharmacological interventions for sex offenders or drug addicts. Other forms of brain interventions to combat criminal behavior are, at this point, guesses, though guesses with some basis in science.

\section{A. Pharmacological Treatments}

The criminal justice system has used pharmacological treatments to try to control crime in at least two major respects: chemical castration for sex offenders and pharmacological interventions for drug or alcohol addicts. In addition, mentally ill people in the criminal justice system (and outside it) have sometimes been compelled to take drugs to treat their mental illness. Other pharmacological interventions against crime seem plausible but do not appear to have been widely discussed.

\section{Chemical Castration}

The best example of pharmacological treatment for criminal behavior is "chemical castration for sex offenders." "Starting in the mid-1990s, several American states authorized the use of so-called chemical castration on various sex offenders, ${ }^{12}$ following the lead of

11. Writing on castration provides an interesting insight into published legal scholarship. A quick search of the Lexis database for articles with the U.S. and Canadian Law Reviews database turned up thirty-one law review articles on the subject. One used the term metaphorically; the other thirty were about castration of sex offenders. One of the thirty articles was published in 1994; twenty-four of the thirty were published in either 1997 or 1998 . Since then, one was published in years 1999, 2001, 2005, 2006, and 2007. Twenty-two of the thirty publications were law student work. (Subsequent searches turned up at least two more articles, one published in 1993 and one in 1998.) Apparently when a "sexy" topic emerges, it will lead to an outpouring of student works with very little follow-up.

12. As noted above, more than thirty law review articles discuss these castration statutes. This discussion relies primarily on J. Michael Bailey \& Aaron S. Greenberg, Lessons from the Morse Case, 92 Nw. U.L. REv. 1225 (1998); Lystra Batchoo, Voluntary Surgical Castration of Sex Offenders: Waiving the Eighth Amendment Protection from Cruel and Unusual Punishment, 72 BROOK. L. REv. 689 (2007); Stinneford, supra note 9; William Winslade et al., Castrating Pedophiles Convicted of Sex Offenses Against Children: New Treatment or Old Punishment?, 51 SMU L. REV. 349 (1998); Caroline M. Wong, Chemical Castration: Oregon's Innovative Approach to Sex Offender Rehabilitation, or Unconstitutional Punishment?, 80 OR. L. REV. 267 (2001); Recent Legislation, Constitutional Law-Due Process and Equal Protection-California Becomes First State to Require Chemical Castration of Certain Sex Offenders, 110 HARV. L. REV. 799 (1997). 
some northern European nations. ${ }^{13}$ Chemical castration refers to a regular series of injections of a drug known as medroxyprogesterone acetate ("MPA") and sold under the trade name of Depo-Provera. ${ }^{14}$ Depo-Provera has long been an approved method of birth control for women. When given to a man, it greatly lowers the man's testosterone level. The results include difficulty in (but not always impossibility of) having erections or ejaculations, as well as (and apparently more importantly for crime control) a sharp decline in sexual thoughts and impulses. $^{15}$

Currently seven states have statutes expressly authorizing chemical castration of at least some male sex offenders. California, Florida, Louisiana, Montana, and Iowa - states with nothing obvious in common beyond names that end in "a"-require chemical castration for certain classes of sex offenders. ${ }^{16}$ The relevant offenses are defined broadly in some states and narrowly in others; some states only require treatment for second offenders, while others allow it on the first conviction. Oregon has a pilot program with only a small number of carefully selected offenders forced to undergo the treatment. ${ }^{17}$ All of these states require the treatments to start shortly before release from prison and to continue either until the state no longer deems it necessary (California, Florida, Montana, and Iowa), or until the end of parole or post-prison supervision (Louisiana and Oregon). ${ }^{18}$ Wisconsin's statute is more discretionary, authorizing, but not requiring, the state Department of Corrections or Parole Commission to make chemical castration a condition of probation or parole in individual cases. ${ }^{19}$

An eighth state, Texas, does not authorize chemical castration, but expressly provides that certain convicts may voluntarily choose surgical castration. ${ }^{20}$ Four of the seven chemical castration states allow voluntary surgical castration as an alternative. Unlike chemical castration, where the effects wear off quickly without regular administration of the drug, surgical castration is permanent (although some of the effects can be reversed by male hormone injections).

13. Denmark, Norway, the Netherlands, Germany, and Switzerland all authorize either surgical or chemical castration for some sex offenses. See Wong, supra note 12, at 270.

14. Other drugs have been considered for use, or have been used in other countries, for chemical castration, but MPA is the drug used in the United States.

15. See Stinneford, supra note 9 , at 573 .

16. See id. at $578-82$.

17. $I d$. at 580 .

18. Id. at 578 .

19. Id. at 581 .

20. Id. 


\section{Anti-Addiction Programs}

Some addiction treatment programs provide a second example of pharmacological interventions against crime. These programs use FDAapproved drugs to combat drug or alcohol addiction, sometimes by themselves but usually in conjunction with other anti-addiction counseling and treatments. Participation in such programs may be required as a condition of probation or parole or, more commonly, may be ordered by "drug courts." Each of these pharmacological treatments for addiction is somewhat effective but none is broadly successful. ${ }^{21}$

Addiction to heroin or other opioids (such as morphine, oxycodone, hydrocodone, and fentanyl) can be treated with methadone, which prevents withdrawal symptoms and reduces the craving for heroin, while avoiding many of the risks and harms of heroin. Methadone, a synthetic opioid, works as an "agonist" with respect to heroin-it attaches itself to the same receptors on brain neurons as heroin does and causes a response in them, but causes no euphoria. The patient has, in effect, substituted methadone addiction for the more damaging heroin addiction. Patients in methadone maintenance programs typically receive their dose by a daily pill, usually administered at the treatment center. Since 2002, another opioid, buprenorphine, has also been approved in the United States for treatment of opioid addiction. The use of both methadone and buprenorphine to treat drug addiction is heavily regulated by both federal and state governments.

Naltrexone, like methadone, is a synthetic opioid. Naltrexone blocks the opioid receptors without eliciting a response from neurons, preventing other opioids from binding to them. Because Naltrexone eliminates or attenuates the opioids' effects, it can be used to treat opioid addiction. It does not prevent cravings for the opioid and so is mainly useful in highly motivated patients. Naltrexone is usually administered by a daily pill, but in 2006 the FDA approved an injectable version whose effects last for thirty days. ${ }^{22}$

Naltrexone is also one of three drugs used against alcohol addiction, although it is not clear how it works. Alcohol addiction also is sometimes treated with disulfiram (sold as Antabuse), a drug that does not diminish the craving for alcohol but that makes its consumption

21. Nicotine addiction also can be treated with some increased success through drug therapy in the form of nicotine replacement therapy. The smoker gets the nicotine to which he or she is addicted but without the manifold dangers of cigarette smoke. Nicotine addiction, however, is rarely associated directly with criminal behavior.

22. FDA Approvals: Vivitrol, Apr. 20, 2006, http://www.medscape.com/viewarticle/530353. 
extremely unpleasant, causing vomiting, headaches, and severe flu symptoms. Acamprosate is a third drug for alcoholism that the FDA recently approved. It seems to work more directly on neurotransmitter levels and to limit the effects of alcohol withdrawal. ${ }^{23}$

\section{Mandatory Treatment with Anti-Psychotics}

Although it is not part of the criminal sentencing process, the United States does have substantial experience with mandatory treatment of the mentally ill-as prisoners, criminal defendants, or inmates in mental hospitals-with anti-psychotic drugs. The Supreme Court has held that anti-psychotic drugs can only be administered involuntarily under certain conditions. It allowed the involuntary use of anti-psychotic drugs on prisoners when it had been appropriately determined that "the inmate is dangerous to himself or others and the treatment is in the inmate's medical interest." ${ }^{24}$ The Court has upheld forced administration of antipsychotic drugs when necessary to make a defendant competent to stand trial (under some conditions), ${ }^{25}$ but has overturned convictions where criminal defendants were forced to take anti-psychotic medication during their trials in the absence of a determination that the use of the drug was necessary. ${ }^{26}$ And, in Singleton v. Norris, the Eighth Circuit, en banc, held that a condemned prisoner who was properly subject to mandatory anti-psychotic medication, for the protection of himself and others, could be forced to continue taking the medication in order to be competent to be executed. ${ }^{27}$

Of more direct interest are cases where probation or parole was conditioned on taking unwanted psychotropic medication. In at least two cases, federal courts have held that parole or supervised release could not be conditioned on agreeing to take psychotropic medications unless there was a judicial finding that the medication was necessary. ${ }^{28}$ In a third case, the court intimated as much but remanded the case to the district

23. Varenicline, an anti-nicotine addiction drug, sold as Chantix, is also reputed to be effective in treating alcohol addiction, based, in part, on a study in rats. The FDA has not approved it for that purpose.

24. Washington v. Harper, 494 U.S. 210, 227 (1990).

25. Sell v. United States, 539 U.S. 166, 188 (2003).

26. Riggins v. Nevada, 504 U.S. 127, 134-35 (1992).

27. Singleton v. Norris, 319 F.3d 1018, 1026 (8th Cir. 2003), cert. denied, 540 U.S. 832 (2003).

28. U.S. v. Williams, 356 F.3d 1045, 1055 (9th Cir. 2004) (anti-psychotic drugs); Felce v. Fiedler, 974 F.2d 1484, 1495 (7th Cir. 1992) (anti-psychotic drugs). 
court, which had initially dismissed it as frivolous, for that court's full consideration of the issue. ${ }^{29}$

\section{Other Treatments}

One could imagine other treatment regimes, such as requiring convicts with violent impulses to use tranquilizers or sedatives, but there seems to have been little research or activity in this area. There have been at least two litigated allegations that prison or mental hospital officials were experimenting with psychoactive drugs on inmates in efforts to control their behavior. Both of these cases seem to have involved drugs that caused fear or pain as part of so-called aversive therapy, not drugs with a direct effect on criminal behavior. ${ }^{30}$

Apart from the ongoing interest in chemical castration, addiction treatment, and some uses of anti-psychotic drugs, current interest in pharmacological reduction of criminal behavior seems limited. Some evidence exists that antidepressants reduce at least some kinds of aggressive behavior. ${ }^{31}$ There is also discussion in the literature of the hoped-for development of drugs to treat various impulse control disorders, some of which are related to criminal behavior. ${ }^{32}$

This very limited interest may result from the problems of enforcing a mandatory drug program on non-institutionalized persons. Those required to take the drugs may skip their dose, take too little, or take too much, but this problem does not seem insurmountable. If the drug were taken infrequently enough, it might be practical to require the person to come to a monitored location to take the drug, or to receive it by injection or intravenous infusion. Because they would be greater invasions of bodily integrity than swallowing a pill, injections or infusions might face a higher legal hurdle. Another option would be to require regular screening for the drug; a subject without a sufficient blood level of the drug could be deemed in violation of the treatment.

\footnotetext{
29. Bundy v. Stommel,168 Fed. App'x. 870, 873 (10th Cir. 2006) (Prozac).

30. In one of the cases, Mackey v. Procunier, 477 F.2d 877 (9th Cir. 1973), there is no indication whether the plaintiff's allegations of unauthorized experimentation were true. In the second case, however, the Iowa Security Medical Facility was found to have injected inmates who had violated the rules with a drug called apomorphine, which caused fifteen minutes to an hour of vomiting, as part of an experimental "aversive therapy." Knecht v. Gillman, 488 F.2d 1136 (8th Cir. 1973). That court enjoined this "therapy" unless done by medical professionals and with the inmates' informed consent.

31. See Alyson J. Bond, Antidepressant Treatments and Human Aggression, 526 EUR. J. PHARMACOL. 218 (2005).

32. Stephen J. Hucker, Impulse Control Disorders, http://www.forensicpsychiatry.ca/impulse /overview.htm (last visited Mar. 27, 2008).
} 
Many probationers or parolees already have to undergo screening for use of illegal drugs; adding a test for a therapeutic drug may not be difficult. Finally, timed-release versions of the drugs might be created that kept the subject from changing the dose. These could be similar to Norplant, a birth control drug inserted under the skin of the arm that remains effective, if not removed, for five years. Ultimately, the lack of discussion of pharmacological control of criminal behavior probably stems from a shortage of effective drugs. If increased knowledge of the brain were to produce effective drugs, their use would likely be considered.

\section{B. Psychosurgery}

Neurosurgery has been used to control neurological diseases, such as some kinds of intractable epilepsy, as well as aberrant behaviors. In the latter context it is called "psychosurgery." Perhaps the most famous, or infamous, kind of neurosurgery for behavior modification is the frontal leucotomy or leukotomy, better known as the prefrontal lobotomy, for which Egas Moniz won the Nobel Prize in Medicine in 1949.

This procedure involves severing the connections between the frontal cortex and deeper parts of the brain. ${ }^{33}$ It was used for several decades to treat a wide range of psychiatric conditions, including depression, bipolar disease, obsessive-compulsive disorder, and schizophrenia. It was reported to have calmed and made more manageable many of its subjects; it also frequently produced profound personality changes, particularly severe apathy, and at least in some cases severe cognitive deterioration. The procedure faded from use with the development of the first generation of anti-psychotic drugs in the mid-1950s and ultimately was discredited, particularly in popular culture. ${ }^{34}$ Over 30,000 Americans received lobotomies, although I can find no record that it was ever used as part of a criminal sentence. ${ }^{35}$

33. See Victor W. Swayze II, Frontal Leukotomy and Related Psychosurgical Procedures in the Era Before Antipsychotics (1935-1954): A Historical Overview, 134 AM. J. PsyCHIATRY 505 (1995).

34. Ken Kesey's One Flew Over the Cuckoo's Nest provided probably the most powerfully negative fictional depiction of a lobotomy, echoed in the extremely successful movie made from the book in 1975. (The movie, which starred Jack Nicholson as the eventually lobotomized protagonist, Randall McMurphy, won all five major Academy Awards - best picture, best actor, best actress, best director, and best screenplay.)

35. The number of Americans who received prefrontal lobotomies is not entirely clear. One frequently finds references to 40,000 or 50,000 subjects of the surgery. Swayze cites sources that concluded that just over 18,600 prefrontal lobotomies were performed by June 30,1951. Swayze, supra note 33 , at 511 . He then cites another source for the position that probably not more than 
There seems to be little current interest in psychosurgery as a treatment for criminal behavior in general. In part this may stem from the stigma that has attached to the field since the demise of the prefrontal lobotomy. But it is also the case that a plausible neurosurgical remedy would require some kind of "criminal brain region" that could be destroyed or isolated.

The use of functional magnetic resonance imaging (fMRI) and other forms of neuroimaging has sparked great interest in correlating activity in particular regions of the brain with mental states or behaviors. The neuroscience of crime seems to have focused more on underactive regions, not overactive ones, at least in recent years. ${ }^{36}$ In the past, though, the surgical removal or destruction of the amygdala was explored as a way to control extreme aggressiveness. There appears to have been substantial research with this method through the 1960s and 1970 s, but its use has "geometrically decreased" in the last twenty years. $^{37}$ Given the many known functions of the amygdala, it seems unlikely that the procedure will regain popularity. At least one researcher in Japan experimented in the early 1960s with destruction of portions of the hypothalamus to treat aggressive behavior, ${ }^{38}$ but this procedure seems not to have caught on. As a result, there seems to be little or no neurosurgical research currently aimed at criminal behavior, whether through aggression or otherwise.

The one notable exception is addiction, which some researchers have associated with activity in particular brain regions. There have been some substantial recent efforts to use neurosurgery to treat addiction. Wayne Hall, an Australian expert on addiction, has written about two such efforts. In China, over 500 patients had a structure in their brains called the nucleus accumbens ablated before the Chinese government halted the procedure in 2004. This brain region seems to be involved in the "reward" experienced by users of many drugs of abuse. In a similar effort, over 300 patients in Russia had a different brain region, the cingulate gyrus, removed. This area is thought to be involved in compulsive behaviors. The Russian government stopped these efforts in

10,000 of the procedures were performed between 1952 and 1955, though he argues that that number is probably low. Id. Allowing for a few procedures after 1955, a total of 30,000 seems a reasonable estimate.

36. See Mobbs et al., supra note 2, at 693-94.

37. Kostas N. Fountas \& Joseph R. Smith, Historical Evolution of Stereotactic Amygdalotomy for the Management of Severe Aggression, 106 J. NeUROSURG. 710, 710-13 (2007).

38. K. Sano et al., Postero-Medial Hypothalamotomy in the Treatment of Aggressive Behaviors, 27 CONFINIA NEUROLOGICA 164, 164-67 (1966). 
2002. In neither case was there any formal approval of the procedure as either safe or effective. ${ }^{39}$

\section{Deep Brain Stimulation}

Deep brain stimulation ("DBS") is a different method of affecting brain function. While neurosurgery is essentially destructive, DBS is not. In DBS, one or more thin, insulated wires, called "leads," typically containing four electrodes, are surgically implanted quite precisely into particular regions of the patient's brain while a battery-powered "implanted pulse generator" is implanted under the shoulder or in the abdomen. The implanted pulse generator is then set to provide electrical stimulation through the leads at a particular voltage and frequency, which the physicians can change. ${ }^{40}$ In some applications, the patient is able to turn the stimulation off and on.

That DBS sometimes works is clear. Over the past decade the United States Food and Drug Administration ("FDA") approved DBS for treatment of Parkinson's disease, essential tremor, and dystonia. ${ }^{41}$ How it works, however, is not very clear. In some situations the added electrical stimulation increases the activity by nearby neurons; in others, it represses it. The implantation procedure carries all the risks of neurosurgery. In addition, DBS sometimes has psychiatric side-effects, ranging from compulsive gambling and hypersexuality to hallucinations, apathy, and depression. The side effects can often be mitigated or eliminated by changing the stimulation voltage and frequency and are also thought to be largely-if not entirely_reversible by removal of the DBS.

DBS has also been used, but is not yet generally accepted, for other problems, including chronic pain, ${ }^{42}$ cluster headache, ${ }^{43}$ and Tourette's syndrome $^{44}$ as well as affective disorders such as depression ${ }^{45}$ and

39. Wayne Hall, Stereotactic Neurosurgical Treatment of Addiction: Minimizing the Chances of Another "Great and Desperate Cure," 101 ADDICTION 1, 1-3 (2006).

40. Morten L. Kringelbach et al., Translational Principles of Deep Brain Stimulation, 8 NATURE REVIEWS NEUROSCI 623, 623 (2007)

41. See id.

42. Id.

43. $I d$.

44. Linda Ackermans et al., Deep Brain Stimulation in Tourette's Syndrome: Two Targets?, 21 MOVEMENT DisORDERS 709 (2006); Veerle Visser-Vandewalle et al., Chronic Bilateral Thalamic Stimulation: A New Therapeutic Approach in Intractable Tourette Syndrome, 99 J. NEUROSURG. 1094 (2003).

45. Helen S. Mayberg et al., Deep Brain Stimulation for Treatment-Resistant Depression, 45 NEURON 651 (2005). 
obsessive-compulsive disorder. ${ }^{46}$ There have also been reports of its use to restore consciousness or alertness to a patient in a minimally conscious state ${ }^{47}$ and to treat obesity. ${ }^{48}$ One trial of its use for obesity has recently led to a very surprising increase in the (single) subject's memory, ${ }^{49}$ leading the researchers to begin testing the technique in subjects with Alzheimer's disease. ${ }^{50}$

And, more relevant to the criminal justice system, there is at least one report of the technique having been used to treat "aggressiveness." In 2005 Angelo Franzini and colleagues reported using DBS in the posteromedial hypothalamus on two mentally retarded patients "with aggressive and disruptive behavior and resistant to any pharmacological treatment." The researchers reported "consistent improvement of disruptive behavior in both patients at the follow-up evaluation 1 year later." 52

Different reports have linked parts of the prefrontal cortex to criminal behavior, usually on the theory that the criminals lack appropriate impulse control because of under-activation of those regions. Other areas that have been implicated in criminal behavior include the hippocampus, the amygdala, the corpus callosum, and the hypothalamicpituitary-adrenal axis. ${ }^{53}$ DBS provides a plausible method for stimulating greater activity in regions where diminished function is thought to play a role in crime. It could also provide an adjustable, intermittent, and reversible method of inhibiting activity in areas where over-activity may contribute to criminal activity and thus serve some of the functions of neurosurgery, but without its permanence. Of course, at this stage any such uses of DBS are highly speculative. On the other hand, uses of DBS seem to be spreading rapidly as neurosurgeons try different regions for different conditions. The extension of DBS research

46. B. J. Nuttin et al., Long-Term Electrical Capsular Stimulation in Patients with ObsessiveCompulsive Disorder, 52 NEUROSURGERY 1263 (2003).

47. N. D. Schiff et al., Behavioural Improvements with Thalamic Stimulation After Severe Traumatic Brain Injury, 448 NATURE 600 (2007).

48. Clement Hamani et al., Memory Enhancement Induced by Hypothalamic/Fornix Deep Brain Stimulation, 63 AnNAls of Neurology 119 (2008) and Supplemental Materials, DOI: 10.1002/ana.21295 (2008). The DBS was only temporarily successful for this patient, as the patient eventually turned the stimulator off, resumed binge eating, and regained the twenty-seven pounds he had lost.

49. Id. at $122-23$.

50. Denise Gellene, Deep Brain Stimulation Boosts Memory, L.A. TIMES, Feb. 2, 2008, at A18.

51. Angelo Franzini et al., Stimulation of the Posterior Hypothalamus for Medically Intractable Impulsive and Violent Behavior, 83 STEREOTACT. FUnCT. NEUROSURG. 63 (2005).

52. Id.

53. Mobbs et al., supra note 2. 
to criminality, beyond the one Franzini article, seems likely. Its success is much less certain.

One new method similar to DBS should be noted. Transcranial magnetic stimulation ("TMS") is a non-invasive procedure for stimulating or repressing neuronal activity inside the brain. It works through a magnetic field generated by a coil held close to the outside of the subject's head. The magnetic field penetrates the skull and induces a mild electric current in the brain, which affects the firing of neurons. TMS is being investigated for a wide range of clinical uses, but it remains unclear how well it will work. One problem with the procedure is that it is fairly indiscriminate; the magnetic field within the brain fills a cone-shaped volume pointing inward from the location of the coil outside the skull. Except in the outermost layer of the brain, it cannot be used to affect neurons in a precise location without also affecting shallower neurons. Still, if it could be used to treat criminal behavior, it would avoid the brain surgery and implants needed in DBS and their consequent risks.

\section{Anti-Drug Vaccines}

The last approach, vaccines, seems likely to be restricted to illegal drugs. Researchers - and pharmaceutical companies - are working on vaccines that effectively block drugs of abuse from having any effect. As the use of such drugs is often itself a crime and is also often associated with other criminal behavior, blocking the effects of those drugs might, in theory, significantly reduce crime. In fact, Frank Vocci, the director of treatment research and development at the United States National Institute for Drug Addiction, recently predicted that a cocaine vaccine would be available within one to ten years. ${ }^{54}$

The idea behind drug vaccines is simple - to use the human immune system to prevent the drug of abuse from reaching its target in the brain. The cocaine molecule by itself is too small to generate antibodies in the human immune system. A cocaine vaccine in clinical trials, the so-called TA-CD vaccine, attaches cocaine to a large protein from the cholera bacterium. The body creates antibodies to both the bacterial protein and its attached cocaine. An early trial on 114 people seeking treatment for cocaine addiction showed that cocaine users who were vaccinated were much more likely to reduce their cocaine use significantly than those

54. Hilary Hylton, A Drug to End Drug Addiction, TiME, Jan. 9, 2008, http://www.time.com /health/article/0,8599,1701864,00.html (last visited Sept. 11, 2008). 
who were not vaccinated. ${ }^{55}$ This vaccine is intended for users who want to stop; it may also be possible to vaccinate non-users, including children, so that they "get no kick from cocaine." Researchers are attempting to create similar vaccines for other drugs of abuse, such as heroin and methamphetamine. ${ }^{56}$ None of these vaccines has, as yet, been approved for clinical use and it remains unclear whether any will be, let alone how effective they will be.

\section{SAFETY AND EFFECTIVENESS}

Excitement about advances in neuroscience may combine with the huge interest in reducing criminal behavior to lead to the rapid adoption of new methods to "treat criminal brains." The example of the prefrontal lobotomy is a warning that such methods may well end up doing more harm than good. The criminal justice system should not directly intervene in people's brains unless the intervention has been proven safe and effective. To do so would impose unreasonable costs on a highly unpopular population - unreasonable either because the interventions are unsafe or because they are ineffective, in which case any cost or risk is unreasonable. Yet when it comes to interventions against criminal behavior, proving safety and efficacy is fraught with difficulties, except perhaps for interventions against addiction.

This section of the essay first discusses the history of the lobotomy, then looks at today's regulatory framework for such interventions, before describing some of the special problems of testing the safety and efficacy of these methods. It ends by discussing the risk that interventions might be tried that have not been proven safe and effective.

\section{A. The Prefrontal Lobotomy}

In 1995 Victor Swayze published a broad historical review of prefrontal lobotomy. ${ }^{57}$ According to Swayze, Moniz initially proposed the lobotomy as a controlled surgical procedure for particularly severe cases. Its use quickly expanded, due largely to the efforts of two Americans, Walter Freeman (a neurologist) and James Watts (a neurosurgeon), to a substantially different procedure used in a much wider range of cases. The procedure was never rigorously assessed

\footnotetext{
55. Id.

56. $I d$.

57. The following discussion is based largely on Swayze, supra note 33.
} 
before being put into broad clinical use. Its rapid adoption, particularly in the United States, was at least in part a consequence of concern over a dramatic increase in the number of people in mental institutions. Some efforts were made at the time to determine the efficacy of the procedure; one review of over 9,000 cases in the United Kingdom found that patients were recovered or greatly improved in forty-one percent of the cases. On the other hand, as early as 1949 another researcher concluded that patients who received the procedure improved at the same rate as those who did not. Two reviews in the 1970s ultimately concluded that all of the studies had such severe methodological problems that the efficacy of the procedure during this period cannot be determined.

It was soon clear, however, that the procedure had costs to those who received it. Swayze writes:

Although leukotomy patients appeared to have therapeutic gains in regard to reduced "tension" or violent outbursts, it was apparent as early as the late 1930s that this was not without a price in relation to the effects on personality. By the mid-1940s significant and quite severe changes in patients' personalities were being reported. Hutton ... in England reported one wife saying, "His soul appears to be destroyed; he is not the man I once knew," and in the words of a sister, "He is without soul now." Rylander ... in Sweden reported a mother saying, "She is my daughter but yet a different person. She is with me in body but her soul is in some way lost." Hoffman ... in the United States reported that "these patients are not only no longer distressed by their mental conflicts but also seem to have little capacity for any emotional experiences-pleasurable or otherwise. They are described by the nurses and the doctors, over and over, as dull, apathetic, listless, without drive or initiative, flat, lethargic, placid and unconcerned, childlike, docile, needing pushing, passive, lacking in spontaneity, without aim or purpose, preoccupied and dependent." 58

An increased realization of those costs combined with the development of the first drugs that showed any efficacy against psychosis led to the decline and fall of the prefrontal lobotomy, but not before about 30,000 people had been subjected to the procedure in the United States.

\section{B. The Regulatory Framework}

In the United States no single regulatory framework covers all the possible brain interventions to treat criminal behavior. Pharmacological, DBS, and vaccine interventions are regulated in various ways by the

58. Id. at 507-08 (citations omitted). 
FDA; psychosurgery is not regulated by the FDA at all, but may be subject to some state statutory control.

The FDA regulates pharmacological interventions as drugs, vaccines as biologics, and DBS as a medical device. In each case the manufacturer must prove to the FDA's satisfaction that the intervention is safe and effective before it may be distributed in the United States. ${ }^{59}$ How the FDA reviews new products for safety and efficacy varies across these three areas, but, largely because of the possibilities of "off-label use," the ultimate relevance of the FDA's review process in the existing legal framework is unclear.

Under the federal Food, Drug, and Cosmetics Act, the drug approval process begins when a sponsor seeks FDA permission to begin human tests of the new drug, through an Investigational New Drug exemption (an "IND"). ${ }^{60}$ Once the exemption is granted, the sponsor proceeds with human trials, typically in three phases - a very small Phase 1 to test for safety, a larger Phase 2 to begin testing for efficacy, and a much larger Phase 3 to test for dosage as well as to test for further safety and efficacy. If the results of these controlled clinical trials are favorable, the sponsor will then submit a Premarket Approval Application to convince the FDA that the drug is safe and effective for a particular indication. ${ }^{61}$ At that point, the FDA not only makes a substantive decision about safety and efficacy but, if it does approve the drug, it must agree to the exact wording of the "label" for the product, which sets out the product's dosage, indications, contra-indications, and side-effects. ${ }^{62}$ Achieving FDA approval of a new drug typically takes about ten years and costs hundreds of millions of dollars.

The FDA regulates vaccines under a different statute - the Public Health Service Act-but in a manner fundamentally similar to its regulation of drugs. ${ }^{63}$ The sponsor again must receive an Investigational New Drug Exemption and then proceed through, typically, three phases of controlled human clinical trials. If the trials are successful, the sponsor will submit a Biologicals License Application to convince the FDA that the vaccine is safe and effective for a particular use. If the vaccine is approved, its labeling also requires FDA approval.

59. See 21 C.F.R. $\S 312.20$ (2007). The terms "safe" and "effective" are not, of course, selfdefining. The FDA has substantial discretion in how it applies them; a treatment for deadly pancreatic cancer might be judged safe and effective far more easily than a treatment for teenage acne.

60. See id. $\$ 312.21$.

61. See id. $\$ 314.50$.

62. See id. $\S 314.105$.

63. See 42 U.S.C. $\S 262$. 
Medical devices face similar but weaker regulation. Only new "Class III" devices, those with the greatest risk, must be proved safe and effective through clinical trials, which are allowed only after the FDA has granted the sponsor the device equivalent of an IND, an Investigational Device Exemption (an "IDE"). ${ }^{64}$ These trials are typically much smaller and shorter than clinical trials for new drugs and thus cost only a small fraction of the drug trials. Even among Class III devices, a device that is "substantially similar" to a device that was used before 1976 (the date of the crucial Medical Device Amendments to the Food, Drug, and Cosmetics Act) or that was approved after 1976 may be approved without any new clinical trials through what is called the Section 510(k) process.

All three FDA regulatory systems share a significant loophole, however, called "off-label use." The FDA approves drugs, vaccines, and medical devices only for particular uses - against a particular disease, or with a defined set of patients (children, adults, the elderly). But once the FDA has approved a drug, vaccine, or device for one purpose, a physician may prescribe it for any purpose, limited only by the physician's judgment and potential malpractice liability. ${ }^{65}$ The sponsor is not allowed to "market" an approved drug, vaccine, or device for an off-label use, so it may not advertise it for such a use to the public or to physicians. A drug, vaccine, or device approved for one use may therefore be legally sold and used, but not marketed, for another. Thus, Depo-Provera, approved for use by women for birth control, may be used for chemical castration, or a particular deep brain stimulation device, approved for use for Parkinson's disease, could be used to try to repress criminal behavior. ${ }^{66}$

Oddly enough, the widespread off-label use of approved drugs, biologics, and devices would not trigger FDA regulation, but research into those uses often would. The FDA's regulations provide that research involving an off-label use of a device requires an IDE, at least where the research has to be approved by an institutional review board ("IRB") and the IRB concludes that it involves a "significant risk

64. See 21 C.F.R. $\S 812.2$.

65. See $i d$. $\S 312.2$. Drugs approved for over-the-counter sales by the FDA do not require a prescription and can legally be used by any consumer for any indication. Only a few medical devices are "restricted" and hence the equivalent of prescription drugs; most can be ordered by patients without a physician's approval. Cardiac pacemakers, heart valves, and hearing aids are examples of restricted devices.

66. And, for devices, a DBS device that was substantially similar to an approved device could be approved under Section $510(\mathrm{k})$ without new trials of safety and efficacy. 
device." ${ }^{, 67}$ Similar but slightly different provisions govern off-label research use of drugs and vaccines. ${ }^{68}$

Surgery is not regulated by the FDA, except to the extent that its regulation of devices and drugs has incidental effects on surgical procedures. In the aftermath of the prefrontal lobotomy, many states did regulate psychosurgery. As of 2002, twenty-two American jurisdictions restricted psychosurgery in various ways. ${ }^{69}$ Most of the statutes prohibit involuntary use of psychosurgery or impose special requirements for informed consent, by the subject or the subject's guardian, but their breadth and their specific terms differ widely. Texas, for example, merely exempts psychosurgery from the scope of medical powers of attorney. ${ }^{70}$ California, on the other hand, passed a confusing welter of statutory provisions on psychosurgery in the 1970s. These prohibit involuntary psychosurgery on prisoners ${ }^{71}$ or those in institutions for the developmentally disabled or the mentally ill. $^{72}$ For prisoners who volunteer for psychosurgery, the statute requires that a court determine that "the state has proven, by clear and convincing evidence, that the confined person has the capacity for informed consent and has manifested his informed consent." wherever administered," must meet a complicated procedure for informed consent and for unanimous approval of the surgery on that particular patient by a panel of three physicians other than the treating physician. $^{74}$ Although the statutes use different definitions for psychosurgery, they all seem broad enough to cover DBS as well as destructive psychosurgery. ${ }^{75}$

67. 21 C.F.R. $\S 812.66$ (2007).

68. Id. $\S 312.2$. The main difference is that the investigator, and not the IRB, has to conclude whether the different use significantly increases the risks or decreases their acceptability.

69. Joanmarie Ilaria Davoli, Still Stuck in the Cuckoo's Nest: Why Do Courts Continue to Rely on Antiquated Mental Illness Research?, 69 TENN. L. REV. 987, 1040, n. 282.

70. TEX. HEALTH \& SAFETY CODE ANN. $\$ 166.152$ (2001).

71. CAL. Penal CODE $\S \S 2670.5(\mathrm{~b}), 2670$ (West 2000).

72. CAL. WeLF. \& INST. CODE $\S \S 5325(\mathrm{~g}), 4503(\mathrm{~h})$ (West 1998).

73. CAL. Penal Code $\S 2679$ (West 2000).

74. CAL. Welf. \& INST. CODE $§ 5326.6$ (West 1998).

75. The section dealing with prisoners defines psychosurgery broadly to include "lobotomy, stereotactic surgery, electronic, chemical or other destruction of brain tissues, or implantation of electrodes into brain tissue." CAL. PENAL CODE $§ 2670.5$ (c) (West 2000). The section dealing with non-prisoners defines psychosurgery as:

those operations currently referred to as lobotomy, psychiatric surgery, and behavioral surgery and all other forms of brain surgery if the surgery is performed for the purpose of any of the following:

(1) Modification or control of thoughts, feelings, actions, or behavior rather than the treatment of a known and diagnosed physical disease of the brain. 


\section{Difficulties in Proving Safety and Efficacy}

Between the lack of federal regulation of psychosurgery and the offlabel use loophole in federal regulation of drugs, vaccines, and medical devices, it is not at all clear that neuroscience interventions would have to be proven safe and effective for controlling criminal behavior. Pharmacological interventions against addiction have gone through the FDA's drug approval process, while the use of MPA for chemical castration of sex offenders is an off-label use of the drug approved for use by women for birth control. $^{76}$ Even if there were a general requirement for proof of safety and efficacy, however, such proof, in this context, would be difficult to provide, for both scientific and social reasons. These reasons include the limitations of animal models in dealing with human behaviors and brains, but, more fundamentally, revolve around the practical and ethical difficulties of finding volunteers for clinical trials to test prevention of criminal behavior, as well as the political risks such trials pose.

\section{The Limited Relevance of Non-Human Research}

The relative uselessness of non-human research in studying brain interventions against criminal behavior is an important scientific barrier. Non-human animals have neither the interplay between motives and social norms nor the brains necessary to allow us to put much weight on such testing.

It can no longer be argued that other animals do not act in ways that would be criminal if done by humans. Acts that, done by humans to humans, would lead to charges of murder, rape, and theft have been observed in non-human animals. The problem is whether those behaviors are sufficiently similar in their motivations (and presumably their causal links in the brain) to equivalent human behavior to provide a good test of an intervention to control the human behavior. Male

(2) Modification of normal brain function or normal brain tissue in order to control thoughts, feelings, action, or behavior.

(3) Treatment of abnormal brain function or abnormal brain tissue in order to modify thoughts, feelings, actions or behavior when the abnormality is not an established cause for those thoughts, feelings, actions, or behavior. Id. $\S 5325(\mathrm{~g})$. See also the nearly identical $\S 4503(\mathrm{~h})$.

76. Interestingly, the makers of naltrexone received FDA approval for it both for use in opioid addiction treatment, in 1984, and again for its use to treat alcoholism, in 1994. Presumably, the firm thought the advantages in being able to advertise naltrexone to the large potential market of alcoholics was worth the cost for additional approval. 
chimpanzees in the wild are known to patrol their band's boundaries and to capture, kill, and eat chimpanzees from other bands. If we were able to find an intervention in the brains of chimpanzees that prevented that behavior, how confident would we be that it would prevent similar human behavior?

And, of course, for a complex set of reasons involving cost, ethics, and public relations, chimpanzees or any other great apes are highly unlikely to be used for such research. Extrapolating from the behavior of monkeys to that of humans would be hard; moving from rodent behavior to human criminal behavior seems nearly impossible.

Even if the behaviors were similar, though, the brains are different. Human brains are not, in their essential components, that different from those of other mammals, but humans have a vastly larger cortex, particularly the frontal and prefrontal cortex. To the extent that human criminal behavior involves the cortex, our experimental animals may well have no equivalent brain structures or circuits in which to intervene. Even interventions in brain structures that humans and non-humans have in common, such as the amygdala or the hypothalamus, are likely to have different consequences in humans than in non-humans. The human amygdala is acting and reacting in conjunction with the huge human cortex; the rat amygdala is not.

It is always difficult, and uncertain, to extrapolate from non-human tests to humans - a reason that human clinical trials are almost always required. The non-human experiments might provide useful information about humans; addiction studies with non-humans provide one good example. But in studying this kind of trait - criminal behaviors - in this organ-the brain-non-human experiments seem likely to be of unusually limited help.

\section{Problems of Human Trials - Other than Consent}

Unfortunately, human studies of these kinds of interventions will be unusually difficult. The difficulties can be classed as practical and ethical, though political problems lurk in each category.

Human trials present significant practical problems. Phase 1 trials are studies of an intervention's short-term safety, usually done with a handful of subjects who are typically healthy young adults. (If the intervention is thought to be particularly risky, as are many anti-cancer drugs, sick patients will be used for Phase 1 trials.) The typical FDA Phase 2 or 3 clinical trial is controlled, randomized, and, preferably, double-blinded. Out of a large number of subjects, some receive the intervention, while some receive an alternative drug, a placebo, or 
nothing. A random process is used to determine which subjects get what. And neither the subjects nor the researchers know what any given subject got until the trial results are analyzed, although in many cases a separate Data Safety Monitoring Board will have access to unblinded results during the trial to see whether the trial should be stopped as unsafe.

Phase 1 trials may be practicable for at least some anti-crime interventions, particularly drugs and vaccines. It should not be particularly hard to find a small number of volunteers to take a drug, with presumably reversible effects, in order to assess its short-term effects. The fact that a vaccine will often have long-term, if not permanent, effects on a subject's immune system may make volunteers a bit harder to find, but Phase 1 trials still seem plausible. It seems less likely that healthy volunteers could be found for DBS. The leads are implanted into particular spots in the brain through neurosurgery, with some necessary risks, and the process of adjusting the stimulation can be long and difficult. And it seems highly unlikely that healthy volunteers would be willing to undergo psychosurgery, with its consequent destruction of parts of their brains, to test the procedure's safety. For psychosurgery and, probably, DBS, researchers will need to find affected peoplepeople who engage in the criminal behaviors to be controlled-who are willing to volunteer as test subjects. Finding such volunteers is likely to be very hard.

The same issue of finding affected volunteers will become much more of a problem for all four technologies in Phase 2 and 3 trials, when the number of subjects needed will be measured in the hundreds or thousands. Those trials are usually populated by patients with a particular disease who hope that the experimental treatment will help, or even cure, them. Again, it is not as clear that those who engage in criminal behavior will be eager to volunteer for experimental interventions in their brains to treat their "disorder." There may be enough motivated volunteers for some kinds of interventions, particularly those aimed at addiction and possibly some sex offenders; it seems less likely that other criminals will be so eager to be "treated" for their criminal tendencies, particularly when the treatment will require brain surgery, either for psychosurgery or for DBS implantation. ${ }^{77}$

Assume, however, that sufficient volunteers are found. How does such a clinical trial work? Presumably, a large number of people are randomized into a treatment group, receiving the drug, psychosurgery,

77. Note that to the extent criminal behavior is correlated with anti-social behavior, it may be especially difficult to find altruistic volunteers for these tests. 
DBS, or vaccine, and a control group. The control group might receive a placebo or some other standard treatment. ${ }^{78}$ The trial subjects would then be followed to see whether the treatment reduced the criminal behavior in question (was it effective?) and what, if any, adverse effects it had (was it safe?). In the context of this kind of study, such a trial raises several concerns.

First, in any trial, the subjects need to be sufficiently likely to develop the studied end-points to provide a useful test of the intervention. Testing an intervention against heart attacks in a general but young population would require a huge trial because heart attacks are rare at early ages. To test an intervention against criminal behavior without having an enormous trial, the trial subjects would have to be likely to engage in the studied behavior. Thus, the trial would likely be studying a population drawn from the criminal justice system (or its juvenile equivalent). For particular kinds of criminal behavior, like sex offenses, it may be a specific population. For criminal behavior in general, it will be boys and young men.

Second, the measured end points to the trial will presumably be instances of criminal behavior. Some medical clinical trials use "surrogate markers," such as HIV-load instead of deaths from AIDS, or cholesterol level instead of coronary artery disease, because of the difficulties of running trials large or long enough to measure the true end-points of concern. It is hard to see what the surrogate markers would be for most criminal behavior - self-reported thoughts about committing crimes? If the end-point to be measured is criminal behavior, there are likely to be problems in measuring it. Assuming the subjects do not honestly report all their criminal acts to the researchers, cases of criminal behavior will have to be extrapolated from criminal arrests or convictions, both weak markers. While one could hope that they would be equally weak markers for both the treatment group and the control

78. Some of the interventions might be very hard to make blind, to either the subjects or the researchers. Drugs and vaccines can easily be simulated by placebos or other treatments; psychosurgery and DBS would be more difficult. It seems unlikely that a trial would - or ethically couldundertake the risks to the subjects (and the costs to the trial) of performing sham brain surgery or implanting but not turning on a DBS system. Sham brain surgery was used in at least one clinical trial of a treatment for Parkinson's disease, but not without controversy - even though in that case the holes the surgeons drilled in the skulls of the placebo group did not go all the way through the skull. See Thomas B. Freeman et al., Use of Placebo Surgery in Controlled Trials of a CellularBased Therapy for Parkinson's Disease, 341 NEw ENG. J. MeD. 988, 988-92 (1999); G.R. Gillett, Unnecessary Holes in the Head, IRB: EthICS \& HUM. RES., Nov.-Dec. 2001, at 1; Ruth Macklin, The Ethical Problems with Sham Surgery in Clinical Research, 341 NEw ENG. J. MED. 992, 992-96 (1999); Franklin G. Miller, Sham Surgery: An Ethical Analysis, AM. J. BioETHICS, Fall 2003, at 41; Charles Weijer, I Need a Placebo Like I Need a Hole in the Head, 30 J.L. MED. \& ETHICs 69, 69-72 (2002). 
group, it is possible that the treatment could make the subjects more or less likely to be caught than the control group, adding another uncertainty into the trial.

But the fact that crimes are the studied end-points will cause other, possibly more serious, political problems. Victims of crime, and the general public, may not be happy about a clinical trial that observes criminal tendencies, but does not try to report or stop its trial subjects from committing crimes. The complaint may not be fair; after all, if the trial works, the crime rate should go down for the treated group and should not go up for the non-treated group. Yet the prospect of political unhappiness, public relations problems, and even lawsuits by a crime victim could well give a potential trial sponsor pause.

\section{Consent-Related Problems of Human Trials}

Now take away the assumption that sufficient "true" volunteers could be found to participate in this research. How will such a trial be able to attract hundreds or thousands of subjects who are likely to engage in criminal behavior? The only likely answer is to recruit them from those who are already enmeshed in the criminal justice system by offering them some leniency in return for their participation. But this scenario causes its own set of ethical, legal, and political problems. ${ }^{79}$

The ethical problem comes from the desire to have "true" volunteers for human subjects research and not people who have agreed to take part because of some "undue inducement." The foundational document of research ethics, the Nuremberg Code, begins the first of its ten requirements with:

The voluntary consent of the human subject is absolutely essential. This means that the person involved ... should be so situated as to be able to exercise free power of choice, without the intervention of any element of force, fraud, deceit, duress, overreaching, or other ulterior form of constraint or coercion .... 80

79. It may also create another practical problem. Subjects may behave particularly well during the trial in order to win more lenient treatment (or to win approval for the treatment that in turn will lead to their more lenient treatment). To the extent that the study relies on self-reports from the subjects, they may also lie to improve how effective the treatment appears. If the study is a blinded controlled study, this may not matter as both the treatment and the placebo group will have the same incentives to behave or to lie, but the lack of a control group or flawed or non-existent blinding could cause problems.

80. Trials of War Criminals before the Military Tribunals under Control Council Law No. 10, Vol. 2, 181-82. Washington, D.C.: U.S. Government Printing Office, 1949. 
The problem with using people in the criminal justice system comes from whether a person can be said to be acting without "force,... duress, overreaching, or other ulterior form of constraint or coercion" when participation in the research is likely to reduce the intervention of the criminal justice system in his life.

Those potential subjects might have a variety of connections with the criminal justice system. Some will be imprisoned. Their criminal behavior could be studied in the prison or jail, which would provide them with an opportunity to engage in some but not all varieties of criminal behavior, or after their release. They could be persuaded to volunteer by earlier release or by better conditions while imprisoned, or both. Others could already be "at liberty," but facing criminal charges or probation or parole revocation that might not be pressed if they volunteered for the study. Still others could be currently on probation or parole but could be offered either better terms or an earlier end to their supervised status. In any of these cases, one could easily doubt whether they are "so situated as to be able to exercise free power of choice" ${ }^{" 81}$ when offered a deal for their participation in a clinical trial. It is noteworthy that the Nuremberg Doctors trial dealt mainly with offenses against concentration camp inmates and prisoners of war; protection of prisoners was not an incidental aspect of the Nuremberg Code.

When research involves actual prisoners, this ethical concern has been recognized in the federal regulations governing human subjects research as the so-called Common Rule. ${ }^{82}$ Technically, the "common" part of the Common Rule is Subpart A. Subpart A deals only in passing with prisoners. It requires, for instance, that in assessing whether the choice of research subjects is equitable, an IRB "should be particularly cognizant of the special problems of research involving vulnerable populations, such as children, prisoners, pregnant women, mentally disabled persons, or economically or educationally disadvantaged persons." ${ }^{83}$ It further provides that IRBs must find that "[w]hen some or all of the subjects are likely to be vulnerable to coercion or undue

81. Id.

82. The Common Rule is so called because it was adopted in common by over sixteen federal agencies, almost all of the agencies that perform or fund human subjects research. Each agency is bound by its own version of the Common Rule, but most of them parallel closely the HHS rule, codified at 45 C.F.R. $\S 46$, Subpart A. 45 C.F.R. $\S 46$ (2007). The FDA, although part of the HHS, has its own slightly different version of the Common Rule. 21 C.F.R. $\S \S 50,56$ (2007). The FDA, like most federal agencies, stopped at adopting Subpart A of the HHS version of the Common Rule. The HHS version of the Common Rule also contains subparts B, C, and D, dealing specifically with special issues presented by research on pregnant women, fetuses, and neonates; prisoners; and children.

83. 45 C.F.R. $\S 46.111(a)(3)$ (2007). 
influence, such as children, prisoners, pregnant women, mentally disabled persons, or economically or educationally disadvantaged persons, additional safeguards have been included in the study to protect the rights and welfare of these subjects." 84

But the Department of Health and Human Services (HHS) regulations governing human subjects research goes beyond Subpart A to include, in subparts $\mathrm{B}, \mathrm{C}$, and $\mathrm{D}$, respectively, special protections for women, fetuses, and neonates; prisoners; and children. Subpart C states:

Inasmuch as prisoners may be under constraints because of their incarceration which could affect their ability to make a truly voluntary and uncoerced decision whether or not to participate as subjects in research, it is the purpose of this subpart to provide additional safeguards for the protection of prisoners involved in activities to which this subpart is applicable.

The regulations define the term "prisoner" broadly to include those in any "penal institution" as a result of a criminal or a civil statute or confined before trial or sentencing, as well as those in "other facilities" as a result of criminal diversion programs. ${ }^{86}$ Section 46.306 limits permissible research with prisoners to only four categories. The first category seems the most relevant for research into controlling criminal behavior: "Study of the possible causes, effects, and processes of incarceration, and of criminal behavior, provided that the study presents no more than minimal risk and no more than inconvenience to the subjects ...." 87 Note, though, that the language talks about "causes, effects, and processes... of criminal behavior," not the control of criminal behavior. More importantly, it only authorizes "no more than minimal risk" research. Research into new uses of drugs, devices, vaccines, or surgery is highly unlikely to qualify as "minimal risk."

Two of the other three categories might be stretched to include such research. One involves "[r]esearch on conditions particularly affecting prisoners as a class (for example ... research on social and psychological problems such as alcoholism, drug addiction and sexual assaults)." ${ }^{88} \mathrm{~A}$ propensity to engage in criminal behavior probably qualifies as a condition "particularly affecting prisoners as a class," though that seems a bit tautological. The other authorizes "[r]esearch on practices, both

\footnotetext{
84. Id. $\S 46.111(\mathrm{~b})$.

85. Id. $\S 46.302$.

86. Id. $\S 46.303(\mathrm{c})$.

87. Id. $§ 46.306(\mathrm{a})(2)(\mathrm{i})$.

88. Id. $\$ 46.306(\mathrm{a})(2)(\mathrm{iii})$
} 
innovative and accepted, which have the intent and reasonable probability of improving the health or well-being of the subject." ${ }^{\circ 9}$ Again, one could certainly argue that preventing criminal behavior would improve the "health and well-being of the subject," but such an argument feels more than a little Orwellian. This provision also requires that the intervention have a "reasonable probability" of success, which may be difficult to meet. Each of these provisions requires the Secretary of HHS to consult "with appropriate experts including experts in penology medicine and ethics, and published notice, in the Federal Register, of his intent to approve such research...."90 That consultation and public notice provision will serve to deter at least some such research.

Finally, even if the research is for a permissible purpose, the IRB approving it $^{91}$ must find, among other things, that:

(2) Any possible advantages accruing to the prisoner through his or her participation in the research, when compared to the general living conditions, medical care, quality of food, amenities and opportunity for earnings in the prison, are not of such a magnitude that his or her ability to weigh the risks of the research against the value of such advantages in the limited choice environment of the prison is impaired;

(3) The risks involved in the research are commensurate with risks that would be accepted by non-prisoner volunteers ... . ${ }^{92}$

So there will be substantial uncertainties about the legality of doing any research on brain-based criminal behavior controls. If the research is done with prisoners, broadly defined, and either with funding from HHS or by an institution that has given HHS an assurance that it will abide by HHS rules for all its human subjects research (basically all American research universities and institutes), it will have to follow Subpart C. But such research (1) will not fit easily into the only permissible categories of Subpart C, (2) will require the HHS Secretary to consult with an expert group and publish findings, and (3) will be subject to special scrutiny by an IRB. Pharmaceutical, biotechnology, or medical device firms may not have given HHS such assurances and may be able to proceed under the FDA's regulations, which only incorporate Subpart A, but even that

89. Id. § 46.306(a)(2)(iv).

90. Id.

91. The regulation also requires that, for IRBs approving research on prisoners, "[a]t least one member of the Board shall be a prisoner, or a prisoner representative with appropriate background and experience to serve in that capacity ...." Id. $\S$ 46.304(b).

92. Id. § 46.305(a). 
requires special IRB attention to research with prisoners-and the firms would not be able to collaborate with universities.

One might try to do the research with crime-prone subjects who were not "prisoners" under the meaning of Subpart C. That makes the legal situation less complicated. IRB approval will still be needed if the research is being done by an institution that has given an assurance to HHS or, under the FDA regulations, if the research is to be used for an FDA submission, but the special protections of Subpart C will not apply. This "non-prisoner" approach does not lessen the ethical concerns. In some cases it may heighten them; the possibility to avoid prison by volunteering might be even more compelling than the chance to get out of prison early.

Either alternative, however, raises an even more powerful political problem for the research sponsor, akin to (but much more severe than) the public relations and political problem discussed above with "true" volunteers. In addition to looking at criminal behavior in prison, this research will examine the criminal behavior of research subjects outside prison, in the general society. At least some of those subjects will only be free because of the research. Victims of crimes they commit will likely be very unhappy when they learn they were robbed, raped, or assaulted by someone who was only at liberty because of the research. Research sponsors, and the government agencies that offered the favorable treatment that was needed to get research subjects, will have to expect terrible publicity, as well as possible tort litigation. How many pharmaceutical, biotechnology, or medical devices firms, medical schools or universities, and prison or parole systems or prosecutors offices will be willing to take such risks?

\section{The Risk of Inappropriate Adoption of Crime Prevention Treatments}

For a host of reasons, good clinical trials of crime-reducing interventions will be hard to do-and therefore unlikely to be done. That does not necessarily mean that interventions will not be tried. The enthusiastic adoption of the prefrontal lobotomy is one frightening example. In the emotionally (and politically) charged context of crime, the imposition of unproven technical "fixes" on the always unpopular class of "criminals" seems quite plausible. And, in fact, we may already have an example of it - chemical castration. Doubt remains about the effectiveness, focus, and implementation of American chemical castration statutes. John Stinneford's 2006 article reviewed these issues 
in detail and, along with an earlier article by Michael Bailey and Aaron Greenberg, is the basis for the following discussion. ${ }^{93}$

Support for the safety and efficacy of chemical castration comes mainly from European experience with surgical castration. During the twentieth century, various European countries required or allowed surgical castration. ${ }^{94}$ The Nazi regime in Germany required surgical castration for some kinds of sex offenders; West Germany permitted some to choose it in return for lighter sentences. Follow-up studies have been done with offenders surgically castrated in those two regimes as well as other European countries. Bailey and Greenberg report that approximately twenty such studies were done, involving a total of more than 5,000 surgically castrated men. Recidivism rates in all of the studies were quite low, ranging from zero to eleven percent. These studies have a variety of methodological problems, most importantly the lack of a randomly assigned control group (studied offenders who were randomly assigned to not be castrated). The studies also did not generally distinguish between types of sex offenses - some men were castrated for child molestation, others for raping adult women, others for exhibitionism, and some even for consensual homosexual behavior. A study of the West German experience in the 1970s may have been the best; it compared men who chose to be castrated with men who initially agreed to castration but changed their minds. Over an average eleven year follow-up period, the first group had a recidivism rate of three percent; the other group's rate was forty-six percent. (Of course, the fact that the men in the second group had changed their minds could certainly be a confounding factor in the analysis.)

A major problem with this evidence, even apart from the methodological issues, is that it applies to surgical castration, not to chemical castration. It is plausible that MPA treatments would have effects similar to surgical castration, because MPA also quickly reduces testosterone levels, but MPA was never approved by the FDA for use to reduce sex offender recidivism. ${ }^{95}$ Instead, it was approved as a birth control drug at a dose eight to forty times lower than the dose used in chemical castration. The studies conducted on recidivism and chemical castration are few in number, with small sample sizes, and recidivism

93. See Bailey \& Greenberg, supra note 12; Stinneford, supra note 9.

94. One source notes studies of men surgically castrated in Denmark, Germany, Sweden, Norway, Holland, Switzerland, and Czechoslovakia. Ariel Rösler \& Eliezer Witztum, Pharmacotherapy of Paraphilias in the Next Millennium, 18 BEHAV. SCI. \& L. 43, 44 (2000).

95. One of the other drugs used in Europe, cyproterone acetate, has never been used for chemical castration in the United States because, unlike MPA, it has no FDA approved use. Id. at 45. 
rates varying from three percent to eighty-three percent. It is thought to be effective with respect to only some kinds of sex offenses: pedophilia, exhibitionism, and voyeurism. Unlike surgical castration, a one-time procedure, MPA treatment needs to continue permanently or the effects lapse. MPA however, has serious side effects on many who take it, which has reduced compliance with the drug regime (in turn, perhaps, affecting recidivism) and even sparked malpractice litigation. ${ }^{96}$ When used (at much lower doses) in women for birth control, MPA has been linked to bone demineralization, which is in turn associated with osteoporosis, so strongly that a "black box" warning was added to the label in 2004 advising that the drug should not be used for more than two years unless the patient had no alternatives. Whether it causes bone demineralization in men is unknown.

The various American statutes do not necessarily target chemical castration where it has the greatest chance of being effective. Most of them focus on sexual activity with children but the different statutes cover different kinds of offenses. Some of the statutes also cover sexual offenses with adults, either in addition to earlier convictions for sexual misconduct with children or on their own. None of the states requires that a physician, or any other professional, certify that the sex offender have a condition that would be affected by the procedure.

Stinneford also notes that there may well be problems with implementing these statutes. He reports that only Florida and Oregon had information on implementation of their chemical castration statutes. As of April 2005, less than ten percent of those required, by statute, in Florida to undergo chemical castration had received the treatment. In Oregon more than a third of the forty-two offenders recommended for chemical castration had not received it. One reason is that many doctors are reluctant to provide this treatment, out of fear of malpractice liability or because of ethical concerns - concerns that have led the American Medical Association to conclude that judicially-ordered chemical castration is unethical. ${ }^{97}$

Eight American states have adopted chemical castration as a sentence or treatment for some sex offenders. The drug used has never been approved for this purpose by the FDA, and indeed it has some

96. Id. at 47 .

97. See Am. Med. Ass'N., Council on Ethical \& Judicial AfFairs, Court-Initiated MedicAl TREATMENTS IN CRIMINAL CASES, Rpt. 4-A-98, at 4 (1998) (stating that the "AMA opposes ... castration ... initiated solely for criminal punishment."); see also AMA CODE OF MED. Ethics, CourT-INITIATEd Medical TREATMENTS In CRIMINAL CASES, E-2.065 (1998) (stating that "[p]hysicians can ethically participate in court-initiated medical treatments only if [it is] ... not a form of punishment or solely a mechanism of social control."). 
serious side-effects. In addition, the statutes do not try to fit the treatment to those whom it might positively affect, and at least some of the states that have adopted this treatment are having difficulty implementing it. ${ }^{98}$ It may turn out that this treatment is safe and effective for this purpose - or it may not. We do not know.

We do know that few citizens or legislators are very concerned about the rights and safety of sex offenders, many of whom have committed terrible crimes. In light of that, it may be encouraging that only eight states have adopted chemical castration statutes. On the other hand it is clearly evidence that legislators and judges will not always require proof of safety or efficacy before imposing unproven biological treatments on criminals as a way to prevent further crimes. It is not an altogether encouraging sign for the careful control of neuroscience-based brain interventions to prevent crime.

\section{If SAFE AND EFFective TREATMENTS Existed, How SHOUld TheY BE USED?}

What if we had safe and effective (however safety and efficacy are defined) neuroscience-based treatments for criminal behavior? What should we think about in applying them? I will not try, in this essay, to provide in-depth analysis of those questions, but, instead, will point to some areas of concern and a few thoughts on how to proceed.

Specifically, I will not, in this essay, discuss the constitutional questions. They will no doubt arise and be substantial. Challenges could be raised to mandatory treatment under the due process clause of the Fifth and Fourteenth Amendments, under the cruel and unusual punishments clause of the Eighth Amendment, perhaps under a "freedom of mind" application of the First Amendment, or a broader constitutional right of privacy. ${ }^{99}$ If the interventions are not "mandatory" but are chosen "voluntarily" in return for lenient treatment in the criminal justice system, we can expect to see other challenges, including attacks on

98. See supra note 12 and accompanying text.

99. The Ninth Circuit, in a case concerning the alleged aversive therapy to an inmate, held that the prisoner's complaint should not have been dismissed because it alleged that the prisoner was subject to experimentation without his consent. The court held "[p]roof of such matters could, in our judgment, raise serious constitutional questions respecting cruel and unusual punishment or impermissible tinkering with the mental processes." Mackey v. Procunier, 477 F.2d 877, 878 (9th Cir. 1973) (footnotes omitted). For the "mental tinkering" argument, the court cited Eisenstadt v. Baird, 405 U.S. 438, 452 (1972), and Stanley v. Georgia, 394 U.S. 557, 564 (1968), with a cf. cite to Roe v. Wade, 410 U.S. 113, 149-54 (1973). 
whether the choice was truly voluntary or was, in effect, coerced in ways that might be unconstitutional.

Constitutional issues have been discussed in the extensive law review literature about chemical castration. ${ }^{100}$ (Interestingly, they have been scarcely litigated and the four reported cases in the last twenty-four years come from jurisdictions without statutes authorizing castration. ${ }^{101}$ ) They deserve further discussion in the context of the other possible interventions, but not in this essay.

Instead, I want to make several observations that speak more to ethics than to law. For the most part, these thoughts are preliminary and often speculative, some suggestions for further consideration rather than, at this point, conclusions.

My first thought is the least preliminary. We should not view the fact that these possible interventions would intervene directly in a subject's brain as necessarily disqualifying them. Many, but not all, of the justifications for criminal sanctions work by affecting a criminal's brain. Any kind of rehabilitation acts only through changing the criminal's behavior, which works through changing the criminal's brain. Specific deterrence operates, if at all, through changing the outcome of the operations of the deterred person's brain. And the subjective sensation or realization of being punished exists only within the brain of the punished person. Of course, incapacitation, general deterrence, and society's satisfaction with punishment, exist outside the criminal's brain (though the second and third exist through the operations of the brains of others).

100. See supra note 12 .

101. I can find only four reported cases in the modern era dealing with constitutional challenges to chemical or surgical castration. The first two cases were decided in the mid-1980s, more than a decade before the first chemical castration statute. In People v. Gauntlett, 352 N.W.2d 310, 317, modified, 353 N.W.2d 463 (Mich. Ct. App. 1984), a Michigan appellate court held that chemical castration was an unlawful condition of probation, in part because it was unauthorized by statute and in part because it had not been medically accepted. In State v. Brown, 326 S.E.2d 410 (S.C. 1985), the South Carolina Supreme Court summarily reversed plea bargains in which three defendants had voluntarily consented to surgical castration even though the defendants waived appeal. That court found that the sentences were void as violating public policies against cruel and unusual punishment and mutilation. Id. at 412 .

The other two cases were decided in 1999 and 2000. In the first, the Arkansas Supreme Court ruled that the American Civil Liberties Union did not have standing to bring suit on behalf of a criminal defendant who consented to surgical castration as part of a plea bargain. ACLU v. State, 5 S.W.3d 418, 419-20 (Ark. 1999). Interestingly, like South Carolina, Arkansas had (and still has) no statute authorizing either form of castration. In the second, a judge on the Pennsylvania Superior Court set aside a juvenile court disposition requiring that a mentally ill juvenile be evaluated for possible chemical castration, finding that, in the absence of both legislative authorization and clear medical acceptance, the order exceeded the power of the juvenile court. In re R.B., 765 A.2d 396, 397-99 (Pa. Super. Ct. 2000). 
Those effects are the result of physical, biological changes in the criminal's brain. All thoughts and controlled actions appear to be the result of the firings of neurons in the brain. Anything that changes behavior by changing controlled actions will work, ultimately, by changing what neurons fire when and how. (And, of course, if you remember anything from this essay, it will be because reading it has made changes in your brain.) This is not an argument about "free will," but merely an argument that many of the actions the criminal justice system takes act through physical changes in criminal's brains.

Given that, I see no qualitative difference between acting directly to change a criminal's brain - through drugs, surgery, DBS, or vaccines, if proven safe and effective - and acting indirectly - through punishment, rehabilitation, cognitive therapy, parole conditions - to achieve similar ends. It is true that we understand better the likely effects of the traditional methods of trying to change criminals' behavior, including their strong likelihood of failure. Ignorance of a direct intervention's safety and efficacy would certainly be an important strike against its use, but if the intervention is proven safe and effective (again, to whatever standards one applies), direct and indirect interventions seem to me not importantly different.

Thus far, I have just argued that direct brain interventions should not be dismissed out of hand. But under what conditions could they be ethically used? At this point, it seems to me that we can distinguish usefully between some easier, less easy, and downright hard cases.

To fall into the "easy" category, I suggest that an intervention has to meet at least three criteria. First, it must be proven sufficiently effective at preventing future criminal behavior with an acceptable level of risk or harm. Second, it must be accepted voluntarily by an informed, competent adult. And third, it must not cause major changes in the "treated" person's personality, substantial loss of remembered personal history, or significant harm to his cognitive abilities. The first point has been examined; the second and third require more discussion.

An easy case involves a voluntary decision by a competent, informed adult because we normally concede that competent, informed adults have the right to make decisions about themselves. We do not allow competent, informed adults to do anything they want as long as it does not harm others, but we expect there to be some good reason to intervene.

Major changes to the criminal's personality or serious harm to his cognitive abilities may be such good reasons. At least two different rationales seem appropriate. First, one could view a state-sponsored intervention that intentionally made major changes in a criminal's 
personality as equivalent to the death penalty. A person is not, in essence, a body but a personality bound together by the thread of a remembered history. Killing the personality, or killing the memory, kills the person. (A substantial decline in cognitive capacity may not reach quite that level, but if the decline were sufficiently severe, it might qualify.) A biological organism of the species Homo sapiens continues to exist, but it is not the person who began the treatment. Most, if not all, arguments one finds convincing against capital punishment should apply to these kinds of interventions. Even those who do not oppose capital punishment might oppose these kinds of interventions as violating some important aspects of human dignity, even if accepted voluntarily by the criminal. Consider, for example, a voluntarily accepted punishment that put the criminal in a condition similar to advanced dementia. That seems arguably either (or both) the destruction of that person or the intentional and unacceptable degradation of a human. ${ }^{102}$ It is this intuition, I think, that makes the prefrontal lobotomy, at least as its consequences are generally perceived, so unacceptable.

If those are easy cases, a set of somewhat harder cases play around with the criteria of "voluntary decision" and "competent, informed adult." Voluntariness is particularly pertinent in the criminal context. Should an action count as "voluntary" if it is done in preference to criminal punishment, particularly incarceration? The line between hard choices and impermissible coercion is rarely, if ever, easily drawn, in ethics or in law, but a legal analogy may be useful in this context.

The RESTATEMENT (SECOND) OF CONTRACTS describes the defense of "duress" as when "a party's manifestation of assent is induced by an improper threat by the other party that leaves the victim with no reasonable alternative." 103 Threats are improper if they are crimes or torts, are threats of criminal prosecution or bad faith civil action, or a breach of the covenant of good faith and fair dealing, or if the terms are unfair and the threatened action would harm one side without benefiting the other, stems from a prior unfair course of dealing, or "is otherwise a use of power for illegitimate ends."

In the context of criminal sentencing, the convict may be given a choice between a sentence or a course of "treatment." The sentence is,

102. One needs to be careful with this analogy, though. One might argue that a person in the final stages of natural dementia is less than fully human. That argument has a certain plausibility, but is not a position to be taken lightly (and not a position I am either taking or rejecting in this essay).

103. RESTATEMENT (SECOND) OF CONTRACTS $§ 175$ (1) (1981).

104. Id. $\S 176$. 
we will presume, legitimate, imposed with due process of law and intended, one way or another, to protect or benefit society. In that case, the convict's choice is not entirely "free." It is certainly influenced by the knowledge that if he turns down the treatment, he faces, let's say, ten years in prison. Yet that prison term is legitimate, even presumptively just. And the treatment-assuming again that it has been proven safe and effective - is aimed at helping society (and arguably the criminal). We often make hard decisions, faced with real constraints. If the constraints created by the criminal justice system are legitimate, it seems hard to argue that a competent adult may not be allowed to make a choice between them.

On the other hand, it is at least interesting that the nation's only solely surgical castration statute takes a very rigid view of voluntariness. The Texas statute authorizing surgical castration applies only to persons with at least two convictions for specified sexual offenses. ${ }^{105}$ The criminal must be at least twenty-one years old; must be counseled and evaluated by both a psychiatrist and a psychologist; and must, in writing, admit to the last crime, request the procedure, and give informed consent. $^{106} \mathrm{He}$ then must meet with an independent monitor whose duties are to ensure that the criminal received appropriate information about the procedure and that he was not coerced. ${ }^{107}$ Most significantly, the Texas statute forbids castration as a condition of release for parole with mandatory supervision and nowhere authorizes a quid pro quo of any kind to someone who agrees to a surgical castration. ${ }^{108}$

Still harder questions involve decisions to "treat" people who are not competent adults. Children and incompetents lack the capacity legally, and usually ethically, to give full consent. If the intervention is sufficiently useful, should it be applied to them anyway? And if so, under what conditions, and by whom - their parents? A court? One is tempted to approve some kind of "best interests" test, but one does have to worry how well such a test will be (or can be) applied. In the case of a juvenile who is expected to become competent, it may be an easy solution to wait for time to give them the power to decide - unless, of course, for some reason the treatment needs to be started during their minority. For someone incompetent due to mental illness or disability, that option is not available.

105. TeX. GOV’T CODE ANN. § 501.061(a)(1) (2007).

106. Id. $\S 501.061(\mathrm{a})$.

107. Id. $\S 501.601(\mathrm{a}),(\mathrm{f})$.

108. Id. § 508.226. See the discussion in Stinneford, supra note 9, at 581-82. 
The hardest cases, I think, arise with mandatory, involuntary treatments and with treatments with severe consequences. To say those cases are the hardest is not to say whether they are or are not permissible. A sentence of life imprisonment is a mandatory, involuntary intervention and one with substantial consequences for the prisoner's brain (and body). But it seems safe to say that confidence in the safety and efficacy of the treatment should be even stronger when it is used involuntarily than when it is used voluntarily.

In general, it seems to me easier to reject severe interventions, those that wipe out the criminal's personality or memories or that greatly reduce his cognitive abilities. And yet what if an informed competent adult who has been found guilty of heinous crimes asks for such a treatment, one that leaves his body alive but with a substantially new mind, one that can make a new start? Is that a request that cannot ethically be granted?

It is time to return from speculation. In reality, if any neurosciencebased treatments are approved as safe and effective to treat criminal behavior, they will be specific interventions for specific behaviors, with known risks. The hardest questions may never arise; indeed, given the grave difficulties of proving safety and efficacy of such interventions, no questions may arise. On the other hand, we may already have an example: pharmacological treatments for addiction. Methadone, naltrexone, disulfiram, and acamprosate are all drugs used to treat addictions - addiction to opioids for the first two, which almost always results in illegal behavior (if only the illegal use of the opioids), and addiction to alcohol for the last three (naltrexone is used for both). Their voluntary use by competent, informed adults in order to avoid harsher criminal sanctions seems relatively uncontroversial. It may be that, if and when the other methods become real, the appropriate limits of their use may also be, if not clear, at least not terribly difficult.

\section{CONCLUSION}

Our knowledge of the human brain is expanding exponentially. Our concern about crime is high and does not seem to be diminishing. These two realities are going to collide in various ways. I suggest that one significant result of that collision will be efforts to apply neuroscience to "treat" criminal behavior. They have already, in some respects, begun. We need to begin to think about how to deal with such efforts. Specifically, we need to demand that any such treatments have been proven safe and effective, which may require some changes in what kinds of clinical trials we will accept. More broadly we need to begin to 
think about when and how such interventions could be used. We cannot expect, and should not try, to come to conclusions too far in advance of the facts, but we can begin to prepare. If we do not, we may find that neuroscience and the criminal justice system have combined to produce the next great prefrontal lobotomy, which, with or without a Nobel Prize, would truly be a bad thing. 